\title{
EDUCAÇÃO AMBIENTAL NÃO FORMAL: UMA ANÁLISE DE SUA IMPORTÂNCIA SOB A ÓTICA DE PROFISSIONAIS DE MEIO AMBIENTE ATUANTES NA REGIÃO CARBONÍFERA CATARINENSE
}

\author{
Gláucia Cardoso de Souza ${ }^{1}$ \\ Geraldo Milioli ${ }^{2}$
}

Resumo: A região carbonífera catarinense é uma região bastante industrializada. Entretanto, apresenta uma realidade bastante complexa no que se refere aos impactos ambientais cumulativos decorrentes de tal atividade ao longo dos anos. Em contrapartida, a região conta com profissionais da área ambiental, cuja formação é norteada pela educação ambiental e pela busca por padrões mais sustentáveis. Nesse sentido, diante da degradação ambiental característica da região e da contribuição potencial desses profissionais para a reversão do atual cenário, investigou-se qual a importância atribuída à educação ambiental para engenheiro ambiental em suas atividades cotidianas. Os egressos concordam que a mesma compreende um instrumento muito importante, que pode contribuir para a melhoria da qualidade socioambiental da região, empregada preferencialmente por meio de campanhas ou como uma disciplina obrigatória nas escolas. A grande maioria dos entrevistados a emprega em suas atividades cotidianas com frequência, seja atrelada aos processos de licenciamento ou à gestão ambiental.

Palavras-chave: Educação ambiental. Desenvolvimento sustentável. Região Carbonífera Catarinense.

\section{ENVIRONMENTAL NON-FORMAL EDUCATION: ANALYSIS OF ITS IMPORTANCE THE PERSPECTIVE OF ENVIRONMENTAL PROFESSIONALS WORKING IN THE COALFIELD REGION OF SANTA CATARINA STATE}

Abstract: The coalfield region of Santa Catarina is a very industrialized, was forged from the carboniferous activity. Of course, provides a very complex reality in relation to the cumulative environmental impacts resulting from such activity. In contrast, the region has professionals in the environment, whose academic training is guided by environmental education and the search for more sustainable patterns. In the face of environmental degradation characteristic of the region and the potential contribution of these professionals for reversal of the current scenario, which investigated the importance given to environmental education for environmental engineer in their daily activities. The graduates agree that it comprises a very important tool, which can contribute to improving the environmental quality of the region, preferably employed through campaigns or as a compulsory subject in schools. In relation to his employment, it was

\footnotetext{
${ }^{1}$ Mestre em Ciências Ambientais pela Universidade do Extremo Sul Catarinense. Professora substituta pelo Instituto Federal de Educação, Ciência e Tecnologia. gaudesouza@ yahoo.com.br

${ }_{2}$ Doutor em Engenharia de Produção pela Universidade Federal de Santa Catarina. Docente pela Universidade do Extremo Sul Catarinense. geramil@unesc.net
} 
found that the vast majority of respondents employ in their everyday activities often is linked to the processes of licensing or management environmentalist.

Keywords: Environmental education. Sustainable development. Coalfield Region in Santa Catarina State.

\section{EDUCACIÓN AMBIENTAL NO FORMAL: UN ANÁLISIS DE SU IMPORTANCIA EN LA PERSPECTIVA DE LOS PROFESIONALES DEL MEDIO AMBIENTE ACTUANDO EN LA REGIÓN CARBONÍFERA EN SANTA CATARINA}

Resumen: La región carbonífera de Santa Catarina es una región muy industrializada. Sin embargo, hay una situación muy compleja con respecto a los impactos ambientales acumulativos de esta actividad través de los años. En contraste, la región cuenta con profesionales en el área del medio ambiente, cuya formación se guía por la educación ambiental y la búsqueda de modelos más sostenibles. En este sentido, dada la degradación del medio ambiente característico de la región y la posible contribución de estos profesionales a la reversión de la situación actual, se investigó cual es la importancia de la educación ambiental según el ingeniero ambiental en sus actividades diarias. Los egresados están de acuerdo que la educación ambiental comprende una herramienta muy importante, que puede contribuir para la mejoría de la calidad ambiental en la región, empleada preferencialmente a través de campañas o como una asignatura obligatoria en las escuelas. A menudo, la gran mayoría de los encuestados la emplean en sus actividades cotidianas, sea vinculada a los procesos de concesión de licencias o a la gestión ambiental.

Palabras clave: Educación ambiental. Desarrollo sostenible. Región carbonífera de Santa Catarina.

\section{Introdução}

A conservação do ambiente e a busca por padrões mais equilibrados de desenvolvimento representam, indubitavelmente, um dos principais desafios da sociedade moderna. Ademais, reconhece-se que nas atuais circunstâncias a educação ambiental é um instrumento de intervenção indispensável do qual se dispõe para resultados de médio e longo prazo, tendo em vista sua estreita relação com a conscientização e sensibilização em prol de uma reorientação de valores e promoção de comportamentos diferenciados (PELICIONI; CASTRO; PHILLIPI Jr., 2005; RODRIGUES, 2011).

Diante de problemas ambientais multifacetados e da necessidade de saná-los ou minimizá-los, faz-se imperativo destacar o papel da universidade enquanto lócus de problematização, reflexão e capacitação de recursos humanos, no direcionamento de esforços para a reversão dos atuais estágios de degradação ambiental.

O mercado de trabalho de profissionais de meio ambiente abrange várias áreas e a busca por soluções visando a conservação do ambiente está atrelada às estratégias de 
educação ambiental e à implementação de alternativas sustentáveis, sobretudo, no âmbito produtivo.

A região carbonífera catarinense constitui-se por 11 municípios e comporta uma população de mais de 390 mil habitantes. Compreende uma área bastante industrializada, forjada a partir da atividade carbonífera e que se mantém, atualmente, com base em segmentos diversificados: cerâmico, químico, descartáveis plásticos, vestuário e metal mecânico (GOULARTI FILHO, 2002; MILIOLI et al., 2002; MONTIBELLER FILHO, 2009; SEBRAE/SC, 2010).

Em contrapartida ao crescimento econômico regional, ocorre o esgotamento de muitos recursos naturais, uma vez que estas atividades industriais estão vinculadas a significativos processos de desgaste do ambiente, caracterizados pela geração de áreas degradadas, pela contaminação dos rios e lençóis freáticos, somados à poluição atmosférica (MONTIBELLER FILHO, 2009).

Nesse sentido, diante da problemática socioambiental inerente à região carbonífera catarinense, da presença do curso de engenharia ambiental e da importância da educação ambiental e do desenvolvimento sustentável enquanto conceitos e práticas inerentes ao redirecionamento do atual cenário de degradação ambiental, a proposta é investigar qual a importância atribuída a ambos os termos pelo profissional da engenharia ambiental em suas atividades cotidianas.

\section{A Formação Ambiental e a Educação Ambiental}

Pelicioni, Castro e Phillipi Jr. (2005) escrevem sobre a formação e a educação ambiental e enunciam que o desenvolvimento de ações efetivas no que tange à problemática ambiental requer profissionais habilitados, que detenham o domínio teórico necessário sobre saúde, educação, meio ambiente e temas afins, quando da formulação de políticas, programas e projetos na área de meio ambiente.

Tozoni-Reis (2004) avalia que as universidades, mesmo que de forma assistemática, têm contribuído na formação de educadores ambientais atuantes em diversos espaços: escolas, ONGs, instituições públicas e privadas, entidades ambientalistas. A autora pondera, ainda, que o educador ambiental é aquele que media a interação entre os sujeitos e o seu meio natural e social; e sua formação é fortemente influenciada por aspectos sociais, políticos e culturais.

Hori e Renofio (2008) se reportam aos diversos níveis de ensino e especialmente às universidades como lócus apropriado para a formação de profissionais qualificados e críticos no que se refere à problemática socioambiental.

Entretanto, embora se tenha uma variedade de cursos na área ambiental em todo o país, com grades curriculares diferenciadas, a formação de recursos humanos para o trato desse tema pelas universidades deve transcender a simples criação de um espaço acadêmico constituído pela integração ou homogeneização de disciplinas tradicionais (LEFF, 2001).

No que diz respeito à inserção da temática ambiental nas instituições de ensino, Leal Filho (1999) comenta sobre a experiência das universidades europeias. Na Inglaterra, graus acadêmicos em ciências ambientais já eram oferecidos desde a década de 1970. Igualmente, na Alemanha, onde há uma tradição na abordagem técnica de temas ambientais, o assunto faz parte do cotidiano acadêmico há bastante tempo.

No caso das universidades brasileiras, Reis et al (2005) enunciam que a questão ambiental também já é abordada há alguns anos. O processo de internalização 
se acentuou na década de 1970 e especialmente na década de 1980, visto que nesse período tal temática adquiriu importância e divulgação crescentes em razão dos acidentes ambientais e, sobretudo, pelas suas implicações sociais e econômicas.

Bursztyn (1999, p.2) lembra que “[...] a chegada do tema Meio Ambiente se dá a partir de contextos departamentalizados. Primeiro foram os departamentos de Biologia, Química e de Engenharia Sanitária. [...] 93\% das referências ao tema, em 1985, vinham daqueles três campos".

Leal Filho (1999) coloca que na década de 1990 houve uma difusão de cursos sequenciais, tecnológicos e de graduação ligados à temática ambiental, com as mais variadas nominações. Reis et al (2005) corroboram, afirmando que nesse período observou-se uma verdadeira explosão dos cursos de graduação voltados para o meio ambiente no país.

Para Pelicioni, Castro e Phillipi Jr., (2005), o ideal é que os cursos que capacitam educadores ambientais incorporem a percepção integrada da natureza e fomentem uma participação crítica e responsável na solução de problemas ambientais e na gestão do meio ambiente.

Da mesma forma, Hori e Renofio (2008) acreditam que a adoção de alternativas mais sustentáveis e o emprego da educação ambiental com um instrumento de transformação social estão condicionados a profissionais com um conhecimento mais aprofundado a respeito da temática em questão, ou seja, dos aspectos físicos, biológicos e antrópicos que constituem a dinâmica ambiental. Faz-se imprescindível, portanto, uma capacitação abrangente e integrada sobre tais processos.

"A necessidade de um conhecimento integrado surge da constatação que vivemos num mundo complexamente organizado devido ao emaranhado de interações entre os seus componentes físico-químicos biológicos e humanos" (MORAES, 1998, p. 39).

Assim, a educação e a formação ambiental devem ser concebidas como um processo de reflexão e tomada de consciência, levando em consideração a transformação dos atuais métodos de investigação e formação por meio de uma visão holística. Tão logo, a capacitação dos sujeitos - educadores e educandos - não pode ser pensada como uma somatória de conhecimentos artificialmente justapostos (LEFF, 2001; TOZONI-REIS, 2004).

Medina (2000 apud PELICIONI; CASTRO; PHILLIPI Jr., 2005) afirma que a educação deve libertar-se da fragmentação imposta pelo modelo vigente, fundamentado na racionalidade instrumental e econômica e de seus estreitos pontos de vista, unindo-se a outras instituições sociais em busca da construção de um mundo mais humano e sustentável.

Jacobi (2003), assim como Leff (2001), se refere à necessidade de uma perspectiva holística de ação, a qual deve embasar-se na formulação de uma educação ambiental crítica e inovadora, tanto em nível formal quanto não formal.

\section{0 engenheiro ambiental e a educação ambiental}

Pressupõe-se que o conhecimento mais aprofundado e a formação ambiental tornam ainda maior a responsabilidade de profissionais com interface na referida área, quando do direcionamento de esforços para modificar os estágios de degradação onde quer que atuem, vislumbrando a educação ambiental e o desenvolvimento sustentável como referências de mudança, de transformação social. 
Em concordância com Pelicioni, Castro e Phillipi Jr., (2005), faz-se essencial que o engenheiro ambiental seja um profissional com conhecimento teórico e prático acerca de ambas as temáticas, das quais dependerá para qualidade da sua atuação e para sua efetiva contribuição frente aos problemas enfrentados no mercado de trabalho.

Da mesma forma, de acordo com o conceito mais disseminado de desenvolvimento sustentável, o qual prevê que as necessidades do presente sejam atendidas, sem comprometer a possibilidade das gerações futuras de atenderem as suas demandas, o profissional em análise deve ser munido de embasamento teóricometodológico para fazer com que os recursos naturais sejam utilizados de forma racional, adotando medidas preventivas que salvaguardem as condições de perpetuação dos recursos necessários à sobrevivência das gerações vindouras, evitando ou minorando o máximo possível, impactos ambientais futuros.

Hori e Renofio (2008) comentam sobre a necessidade de preocupação, por parte dos cursos de engenharia ambiental com o grau de conscientização de seus alunos, no que diz respeito à visão holística da realidade e à complexidade dos problemas socioambientais. De acordo com os autores, os currículos não devem ser estruturados exclusivamente sob a perspectiva de somar conhecimentos de áreas distintas ou da busca de possibilidades de aplicação prática de determinados conhecimentos.

Leff (2001) deixa bastante claro que os recursos técnicos decorrentes de conhecimentos especializados se aplicam à solução de problemas pontuais, como o tratamento de águas, a reciclagem de lixo, análise de toxidez, emprego de tecnologias limpas e economia de energia. Por isso, o autor adverte que na formação universitária, além da inserção de temáticas pontuais e de novas especialidades aplicativas, a incorporação da complexidade ambiental implica na participação ativa de professores, alunos e de pesquisadores na atualização de programas curriculares e na transformação do conhecimento.

Nesse sentido, ainda que a concepção da engenharia ambiental esteja fortemente associada ao desenvolvimento de tecnologias para a resolução ou minimização dos impactos ambientais, em sua maioria, de forma pontual ou local, esse profissional precisa estar consciente acerca da problemática socioambiental e mais do que isso, sensibilizar-se e portar-se como um ator social gestador de mudanças.

Para tanto, resgatando Jacobi (2003), Zamoner (2008), Hori e Renofio (2008), é imprescindível que a capacitação acadêmica do engenheiro ambiental fomente sua percepção crítica e propicie, quando no mercado de trabalho, a tomada de decisões sob uma perspectiva holística, pautado na legislação e na ética, conforme determina as diretrizes curriculares do curso de engenharia ambiental.

Logo, a formação ambiental não compreende simplesmente um processo de capacitação que busca reciclar e reajustar as habilidades profissionais às novas funções, às normas ecológicas dos processos produtivos ou à criação e controle de tecnologias inovadoras; vai além da assimilação passiva, da reprodução acrítica de um modelo global homogêneo. A formação ambiental é entendida como a construção de uma racionalidade produtiva embasada no potencial ambiental de cada região para um desenvolvimento descentralizado e sustentável (LEFF, 2001). É nessa perspectiva que deve atuar o engenheiro ambiental ou quaisquer que sejam os profissionais envolvidos com o tratamento dos problemas socioambientais.

Dessa forma, em detrimento de uma abordagem reducionista, caracterizada pela ausência, deficiência ou desconsideração de conhecimentos sobre o funcionamento do meio ambiente, bem como, pela adoção de medidas pontuais, corretivas e pouco 
efetivas, o caminho a ser seguido deve oferecer, potencialmente, alternativas duradouras e melhor sucedidas para os problemas ambientais (GUTIERREZ-MARTIN; HUTTENHAIM, 2003).

\section{Caracterização da pesquisa}

A pesquisa caracteriza-se pela abordagem qualitativa, inserida na perspectiva exploratória, cujo método empregado compreende o estudo de caso. A pesquisa qualitativa "[...] parte do fundamento de que há uma relação dinâmica entre o mundo real e o sujeito, uma interdependência viva entre o sujeito e o objeto, um vínculo indissociável entre o mundo objetivo e a subjetividade do sujeito" (CHIZZOTTI, 1991, p. 79).

Com base no objetivo da pesquisa, o estudo em questão caracteriza-se pela perspectiva exploratória, afinal, "[...] pode-se dizer que estas pesquisas têm como objetivo principal o aprimoramento de ideias ou a descoberta de intuições" (GIL, 1994, p. 47) e na maioria das vezes, envolvem levantamento bibliográfico e entrevistas com pessoas que tiveram experiências práticas com o problema investigado.

Desse modo, a pesquisa dividiu-se em dois momentos, a partir dos instrumentos de coleta de dados empregados. Inicialmente, fez-se contato com 208 egressos em engenharia ambiental da universidade localizada na região, dos quais, 185 responderam ao questionário, via contato eletrônico e telefônico. A partir da identificação do perfil desses profissionais, procedeu-se a uma amostragem estratificada proporcional, para verificar quantos seriam submetidos à entrevista.

A técnica da amostragem estratificada implica em dividir a população em subgrupos ou estratos - que já estão divididos de acordo com as categorias de atuação e sobre os diversos estratos procedem-se seleções aleatórias, de forma independente (BARBETTA, 2008).

Tomou-se como critério ou como propriedade relevante, manter a proporcionalidade de acordo com o estrato com o menor número de engenheiros ambientais atuantes. Para tanto, a definição do número de egressos a serem entrevistados em cada estrato baseou-se na proporcionalidade em relação à categoria $\mathrm{em}$ órgão público, que conta com quatro egressos atuantes. A Tabela 1 apresenta o número de entrevistados para cada categoria.

Tabela 1- Definição do número de egressos a serem entrevistados com base na amostragem estratificada proporcional e tomando como critério a categoria com o menor número de engenheiros ambientais atuantes

\begin{tabular}{lccc}
\hline \multicolumn{1}{c}{ Categoria } & N. de egressos & Proporção & $\begin{array}{c}\text { N. de } \\
\text { entrevistados }\end{array}$ \\
\hline Autônomo & 19 & $\div 4$ & $\approx 5$ \\
Empregado & 50 & $\div 4$ & $\approx 13$ \\
Empresário & 5 & $\div 4$ & $\approx 2$ \\
Em órgão público & 4 & $\div 4$ & $\approx 1$ \\
Em mais de uma categoria & 9 & $\div 4$ & $\approx 3$ \\
\hline \multicolumn{2}{l}{} \\
\hline
\end{tabular}

O número de entrevistas está de acordo com a proposta de Bauer e Gaskell (2002), já que deve ficar entre 15 e 25 para cada pesquisador. Portanto, na segunda etapa da pesquisa foram entrevistados 24 engenheiros ambientais. A escolha dos egressos entrevistados foi feita aleatoriamente, de modo que todos os municípios da 
região fossem contemplados, bem como, que contasse com representantes formados desde a primeira até a última turma.

\section{Apresentação e discussão dos resultados}

Conforme os propósitos da presente pesquisa identificou-se a distribuição dos engenheiros ambientais no âmbito da região carbonífera catarinense, de acordo com as categorias de atuação. Constatou-se que dos 185 egressos que responderam ao questionário, 121 estão atuando na área ambiental e 87 deles encontram-se trabalhando na região carbonífera catarinense (Figura 1).

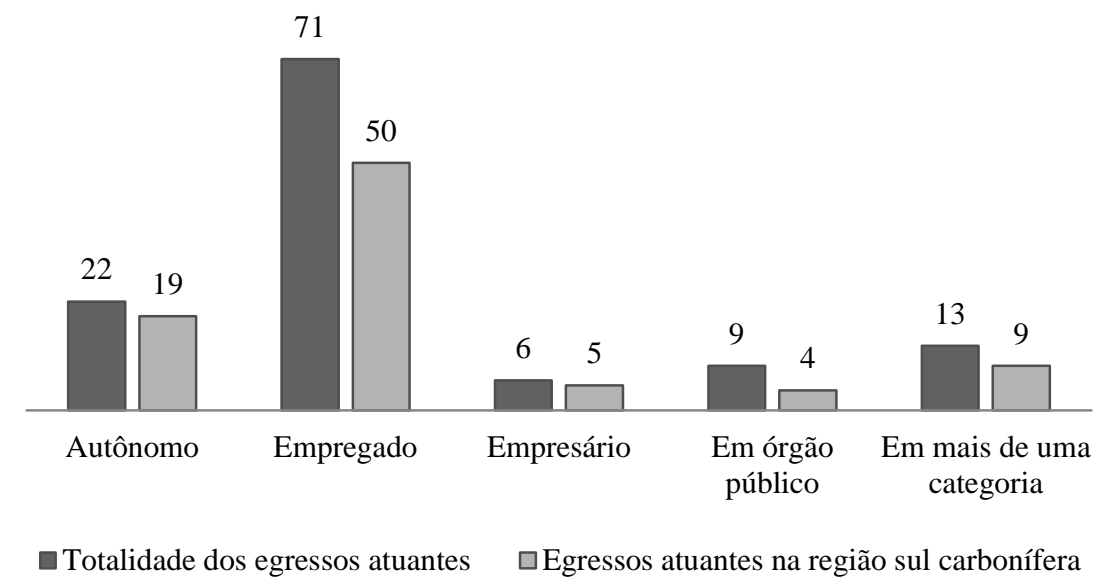

Figura 1 - Distribuição do egresso em engenharia ambiental inserido no mercado de trabalho na sua área de formação acadêmica, de acordo com as categorias de atuação, para a totalidade dos egressos e para aqueles atuantes na região sul carbonífera catarinense.

Dos 121 engenheiros ambientais atuantes, 71 egressos enquadram-se na categoria empregado e destes, 50 trabalham no âmbito da Associação dos Municípios da Região Carbonífera Catarinense (AMREC). Quanto à categoria autônomo, na qual se registrou 22 engenheiros ambientais, percebeu-se que a maioria, 19 egressos, estão alocados na região carbonífera catarinense.

Relacionado àqueles que atuam em mais de uma categoria, dos 13 engenheiros ambientais, nove se encontram trabalhando em um ou mais municípios da AMREC. Em órgão público, verificou-se a presença de poucos egressos na região carbonífera catarinense, visto que dos nove engenheiros ambientais situados na referida categoria, somente quatro trabalham em algum dos municípios da AMREC.

No que se refere aos egressos que tiveram condições de abrir uma empresa na área de meio ambiente, estes representam a iniciativa da minoria dos engenheiros ambientais, afinal, são seis empresas, dentre as quais, cinco se inserem na região em estudo.

Verificou-se no âmbito da região carbonífera catarinense, em relação ao tempo de atuação, que o engenheiro ambiental tem contribuído no tratamento dos problemas socioambientais a ela associados, há no máximo sete anos; um período relativamente curto. Tal situação se assemelha ao que foi exposto por Monteiro e Pasqualetto (2007) 
relacionado à tímida contribuição do engenheiro ambiental em Goiás, onde o curso também teve início no ano de 1999.

Com o propósito de identificar como o egresso está contribuindo, e quais são as áreas de maior demanda na região, questionou-se, aos 24 entrevistados, quais são as atividades desenvolvidas enquanto profissionais da área ambiental, independente de categoria de atuação. As respostas enunciadas foram agrupadas de acordo com a Figura 2.

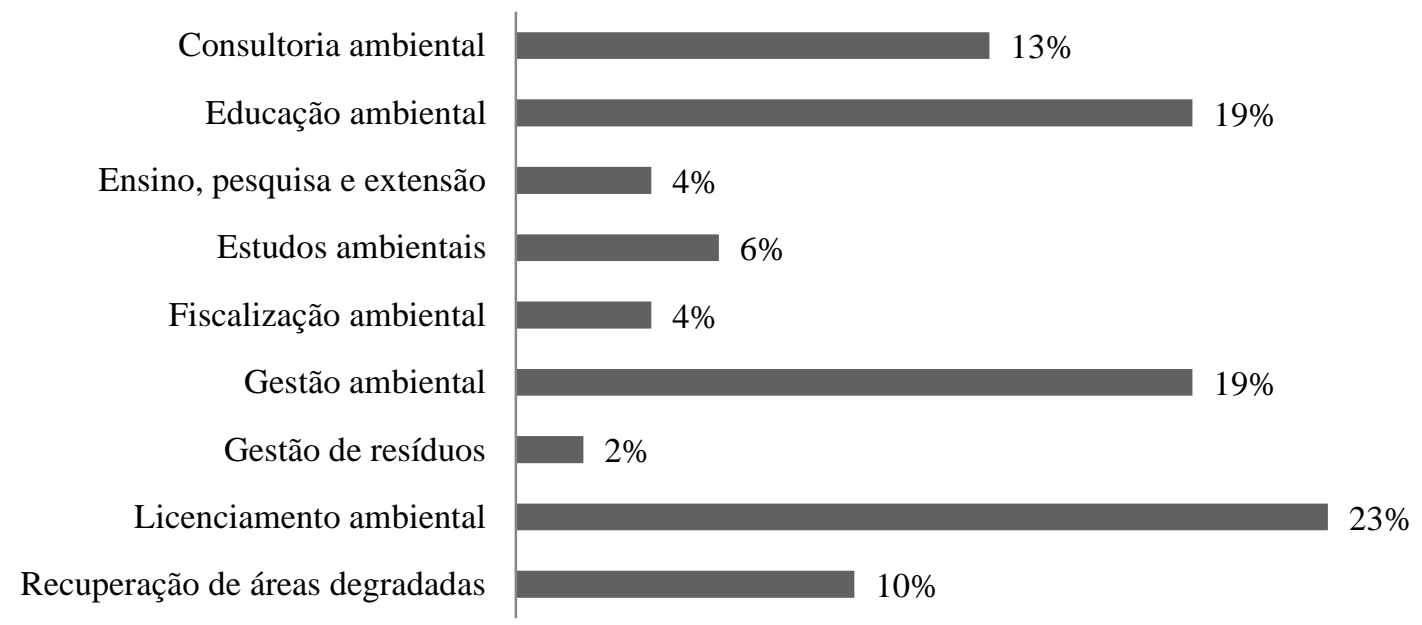

Figura 2 - Atividades desempenhadas pelo egresso em engenharia ambiental atuante na região carbonífera catarinense

Portanto, constatou-se que o licenciamento ambiental é objeto de atuação da maioria dos entrevistados, e é dessa forma que ele tem contribuído para a melhoria da qualidade socioambiental da região. Subentende-se que a educação ambiental, a qual se apresenta da mesma forma com percentual significativo, é empregada tanto nos processos de licenciamento, quanto no âmbito das empresas quando da implantação de manutenção dos sistemas de gestão ambiental. Quanto à relação entre a educação e o licenciamento ambiental e os sistemas de gestão ambiental, destacam-se as seguintes contribuições:

Mesmo em um processo de licenciamento, trabalho com conscientização das empresas. É um diferencial do meu trabalho (E4).

Diretamente, não. Mas informalmente sim. Aliás, temos que fazer isso (E7).

A gestão ambiental é cobrada legalmente, e está associada à educação ambiental (E14).

O trabalho do engenheiro ambiental está embasado na educação ambiental. Não adianta implantarmos ou implementarmos se não tivermos embasados com a educação ambiental (E17).

Tão logo, com a intenção da saber se tal instrumento faz parte do cotidiano do profissional do engenheiro ambiental, perguntou-se aos sujeitos de pesquisa se eles atribuem importância à educação ambiental como referência para melhoria da situação socioambiental da região carbonífera catarinense.

Com exceção de um único entrevistado, os demais se posicionaram favoravelmente à necessidade de empregar a educação ambiental como um instrumento 
de melhoria e reconhecem sua importância para o tratamento da problemática ambiental regional (Figura 3).

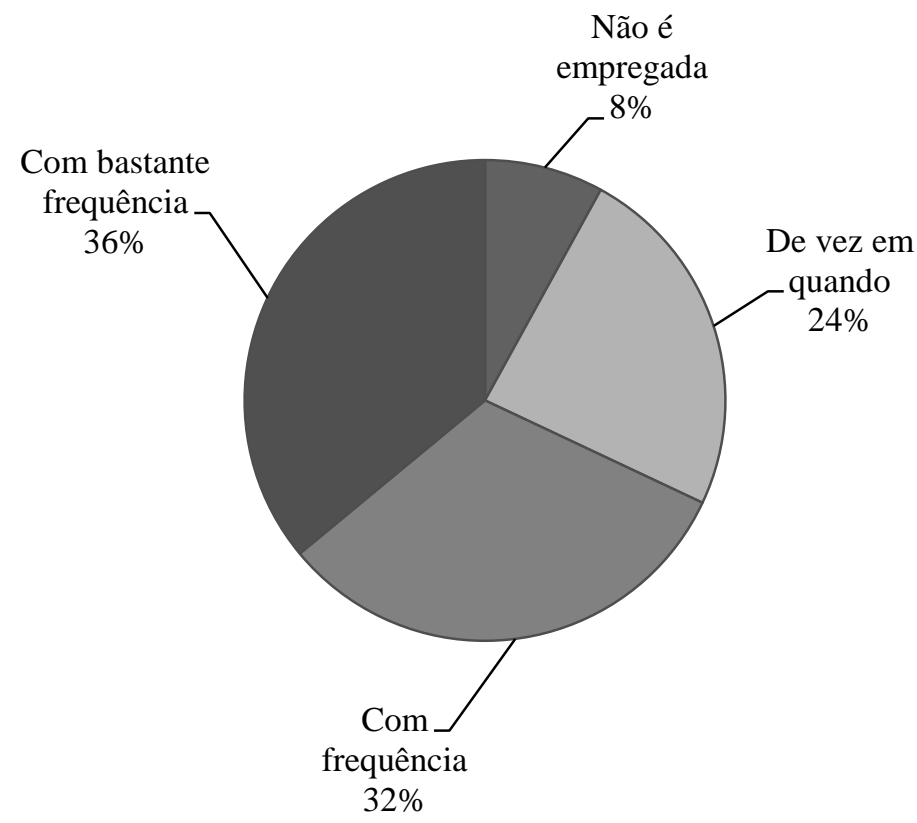

Figura 3 - Frequência com a qual a educação ambiental é incorporada ao cotidiano profissional do engenheiro ambiental

Percebeu-se que a educação ambiental é frequentemente empregada pelo engenheiro ambiental atuante na região; encontra-se fortemente incorporada ao cotidiano desse profissional, visto que $68 \%$ dos entrevistados se referiram às opções com frequência e com bastante frequência. Uma minoria alegou que, no seu trabalho, tal temática não é incorporada ou ainda, que é empregada somente de vez em quando.

De acordo com a maioria dos entrevistados, a educação ambiental poderia contribuir quando empregada por meio de campanhas de conscientização direcionadas para a população, aos empresários ou ainda, pensada como uma disciplina obrigatória no âmbito escolar, preferencialmente nas séries iniciais:

Educação formal, como disciplina obrigatória ou desde crianças (E11).

Desde as fases iniciais. Tem que ensinar na escola. [...] deveria ser uma disciplina como qualquer outra (E18).

Campanhas nas escolas com a crianças. Dá bastante resultado com as crianças (E22).

Penso mais na fase primária. Nas séries iniciais [...]. Ela deveria ser trabalhada muito melhor nas escolas (E24).

A aproximação entre a educação e a questão ambiental é comentada, da mesma forma, por alguns autores (LEFF, 2001; LOUREIRO, 2002; DIAS, 2004; D'AMBROSIO, 2007; RODRIGUES, 2011). Morin (1999), particularmente, assim como o enunciado pelos engenheiros ambientais nas citações acima, se coloca a favor de uma reforma na educação, a qual deve ser iniciada nas séries iniciais; em pequenas classes. 
Nesse sentido, alguns egressos pontuaram sobre a maior facilidade de conscientizar ou sensibilizar as crianças, se comparadas aos adultos. Além de advertir sobre a importância da inserção da educação ambiental no currículo escolar em todos os níveis de ensino, Rodrigues (2011) se coloca, da mesma forma que os egressos e de acordo com Morin (1999), favorável à conscientização das camadas mais jovens:

\footnotetext{
Se tu ensinas uma criança desde cedo, ela vai levar para o resto da vida [...] até uma idade tu consegue ser guiado, ensinado. Se fores educado de maneira errada, depois de uma certa idade, muito difícil de aprender a assimilar, a mudar (E4).

[...] deveria vir desde o início, desde as crianças; porque para os adultos é muito difícil modificar. Deveria ser inserida no ensino fundamental (E6).

Se a criança é educada desde pequena, ela cresce sensibilizada. É uma educação básica (E12).

[...] pra trabalhar com educação ambiental movimentando pessoas de mais idade, não funciona [...] (E24).
}

Não obstante, alguns entrevistados reconhecem a importância da educação ambiental e complementarmente se referiram à educação-adestramento como algo que não deve ser trabalhado ou praticado, assim como campanhas educativas pontuais ou programas isolados.

Da mesma forma, segundo alguns autores (LEFF, 2001; BRÜGGER, 2002; JACOBI, 2003; DIAS, 2004; CARVALHO, 2006), a educação ambiental não pode ser trivializada à perspectiva naturalista ou ecológica, por meio de programas de gestão ambiental ou do treinamento em proteção ambiental. Citam-se as seguintes contribuições que convergem com o exposto:

Na forma de adestramento, não. Se a educação for trabalhada como um todo, sim. [...]. Eu acho que a sociedade adestra as pessoas. A educação ambiental é muito mais do que ver bichinho ou separar o lixo (E4).

[...] acho que camapanhas educativas são muito pontuais e não resolvem o problema. Tem que ser uma educação e não adestramento (E11).

Programas isolados, pra mim, não tem resultados tão expressivos (E15).

Na percepção de parte dos entrevistados, a educação, de modo geral, deveria contemplar a temática ambiental. Não é necessário fazer menção ou distinção entre a educação, de modo geral, e a educação para o meio ambiente:

Entendo que o tema ambiental não precisa ser tratado individualmente. A educação por si só já é ambiental (E1).

Acho que a educação ambiental não é desvencilhada da educação, não deve ser tratada individualmente (E4).

A educação faz com que tu saibas discernir o que é certo e o que é errado [...] (E7).

Diante do exposto, fica evidente que a maioria dos engenheiros ambientais associam ou se referem à educação ambiental como um processo de conscientização com a finalidade de conservação do meio ambiente ou dos recursos naturais:

A educação ambiental está relacionada ao que podemos fazer para cuida do meio ambiente, não prejudicá-lo. Trata-se de uma conscientização da população [...] (E3). 
Tentar fazer com que as pessoas entendam de forma prática, sobre a importância de preservar os recursos naturais [...] (E5).

É um instrumento para conscientizar as pessoas sobre o meio ambiente; o que vai causar; para orientação das pessoas (E6).

[...] é a conscientização das pessoas perante as questões ambientais [...] (E11).

[...] sensibilizar as pessoas com relação aos problemas ambientais [...] (E15).

Vejo a educação ambiental como uma forma de passar conhecimentos para as pessoas, pra que as atitudes delas sejam as mais certas [...] (E19).

Processo de conscientização da população em geral [...] (E21).

No entanto, a preocupação com a conscientização sobre a importância de conservação dos recursos naturais se dá porque o homem se enxerga como parte do todo; como um elemento da teia de relações (CARVALHO, 2006), ou simplesmente porque salvaguardando os recursos tem maiores garantias de sobrevivência? A educação conservacionista discutida por Brügger (1994) ou a polaridade conservadora enunciada por Lima (2002) caracterizam-se, justamente, por essa postura: pela manutenção dos atuais valores com a ressalva de que é preciso promover o uso racional dos recursos naturais.

Ainda nesse sentido, percebeu-se que determinadas contribuições por parte dos entrevistados expressam o emprego da educação ambiental reduzida a um instrumento de gestão ambiental na empresa:

Serve para deixar o ambiente limpo, organizado; evitar proliferação de vetores; destino adequado de resíduos; é a prevenção da poluição (E14).

[...] minimizar os impactos; [...] trabalhar em cima de minimização (E14).

[...] é uma ferramenta de melhoria e controle do que está gerando no meio ambiente $[\ldots]$ (E20).

Uma minoria suscitou que preocupar-se com a conservação dos recursos naturais depende da postura do indivíduo consigo mesmo, do respeito com os limites dos outros; de quão éticas as pessoas são nas suas relações entre elas e, por consequência, com o meio ambiente:

Primeiro é a pessoa ter educação. Uma pessoa que não se preocupa com o outro; valorizar os limites, saber respeitar os limites dos outros. Seja como pessoa ou como empresa. Um cara só vai respeitar o meio ambiente se ele respeita/valoriza o outro. Só isso não é educação ambiental. A questão do respeito, da ética também é educação ambiental [...] (E8).

Ser bem educado presume ética na relação com o meio ambiente, em todos os aspectos de nossa vida (EE1).

É relacionado aos valores éticos (E12).

Você saber os seus limites, até onde tu podes ir [...] (E14).

Desse modo, a conservação dos recursos naturais está atrelada à construção de uma nova sensibilidade com o propósito de corresponsabilização e, consequentemente, de transformação social (CRESPO, 1998; LIMA, 2002; JACOBI, 2003). Afinal, mesmo que as pessoas saibam que determinadas ações podem ter consequências negativas sob o ponto de vista ambiental, embora tenham sido conscientizadas, talvez não se sintam corresponsáveis, principalmente, se os impactos não incidem diretamente sobre a sua vida. 
Convergindo com essa discussão, observou-se que os egressos não se referiram claramente ao conceito de desenvolvimento sustentável. Parte dos entrevistados o visualiza como algo inalcançável, porque, na sua concepção, ele está associado à não geração de impactos ambientais: a impacto zero. Esse é o equívoco, visto que conforme essa ideia, para que se tenha um desenvolvimento sustentável não há geração de absolutamente nenhum impacto; o que os leva a presumir que se trata de uma utopia ou algo de fato impossível de ser buscado. As falas abaixo elucidam a situação descrita:

[...] pra mim é quase uma utopia. Não tenho a percepção de que é impossível gerar impactos ambientais, que os impactos não podem ser gerados (E1).

Hoje se busca muito, mas se tu quiseres viver conforme o desenvolvimento sustentável, tem que desistir de tudo. É possível conciliar algumas coisas [...]. Mas causa impacto da mesma forma (E7).

Eu associo com impacto zero. Dessa forma, acho que não seria possível atividades sem impacto ambiental (E11).

Impactos sempre vão existir (E14).

$\mathrm{Na}$ minha opinião não existe impacto zero; o impacto pode ser minimizado [...] (E19).

Embora não tenham se reportado ao impacto zero, parte dos egressos alegou incompatibilidade entre o desenvolvimento sustentável nos moldes do sistema capitalista ou no âmbito da realidade socioambiental vivenciada nos dias de hoje:

Quase impossível de ser atingida com o atual modelo de crescimento econômico [...] (E2).

[...] é utopia, o que buscamos é se aproximar [...]. Nunca vai haver desenvolvimento sustentável com o sistema capitalista (E4).

Do jeito que tá hoje o mundo, é complicado falar em desenvolvimento sustentável (E23).

Na situação atual é utópico, sobretudo, nessa região. Totalmente utópico (E24).

Há egressos que se referiram de forma acertada, entretanto, alguns fazem as suas ressalvas com relação à possibilidade de implementação desse novo modelo:

Trata-se de um desenvolvimento no presente, que não comprometa tanto as atuais, quanto as futuras gerações [...]. Fala-se muito, mas na prática é complicado de implementar ações de forma efetiva (E3).

Acredito que o desenvolvimento sustentável é possível, mas não como é colocado na literatura. Os conceitos de livros são difíceis de serem implementados (E6).

Produzir degradando o mínimo possível (E13).

Acredito que [...] é conseguir manter as atividades industriais, conciliando conservação do ambiente; não impacto zero; buscar o desenvolvimento dessas atividades buscando menores impactos possíveis [...] (E15).

Cabe ressaltar, sobretudo, a contribuição daqueles que acreditam na possibilidade de buscar outros padrões e, consequentemente, de caminhar no sentido do desenvolvimento sustentável:

Pode ser possível ter o desenvolvimento sustentável. Eu acredito que é possível suprir as necessidades atuais, sem comprometer as das gerações futuras (E5). 
Temos que buscar, é pra isso que existe a nossa profissão [...]. Temos como chegarmos sim, entendendo que a sustentabilidade não é a não geração, mas a minimização (E8).

Eu acredito que é possível [...]. A utilização racional dos recursos ambientais, sem exageros, sem desperdício (E9).

É possível, estamos caminhando para a sustentabilidade [...], estamos no caminho certo; já existem ações direcionadas. Sustentabilidade é igual consumir de maneira ordenada para as futuras gerações (E13).

O conceito mais popularizado de desenvolvimento sustentável está longe de associá-lo a impacto zero. Muito pelo contrário, visto que é impossível, nos dias de hoje, viver sem impactar de alguma forma. Nesse sentido, o engenheiro ambiental precisa ter em mente que a busca por moldes mais sustentáveis é o mesmo que suprir as necessidades da sociedade, em termos de industrialização ou urbanização, impactando o mínimo possível; respeitando os limites da capacidade de recarga dos ecossistemas. De todo modo, para alcançá-lo ou pelo menos contribuir através de padrões mais justos e equilibrados, é preciso saber do que se trata, sobretudo, profissionais da área ambiental como é o caso do engenheiro ambiental.

\section{Considerações finais}

Verificou-se que na região carbonífera catarinense o engenheiro ambiental tem atuado mais expressivamente em atividades correlatas ao licenciamento ambiental, gestão ambiental e educação ambiental. Assim, são essas as atividades mais desempenhadas por esse profissional na região e através das quais têm contribuído.

No que diz respeito à educação ambiental, os engenheiros ambientais concordam que esta compreende um instrumento muito importante, que pode contribuir para a melhoria da qualidade socioambiental da região, empregada por meio de campanhas ou como uma disciplina obrigatória nas escolas; trabalhada preferencialmente com crianças. Em relação ao emprego da educação ambiental pelos egressos, verificou-se que $36 \%$ dos engenheiros ambientais a empregam com bastante frequência, $32 \%$ com frequência, $24 \%$ de vez em quando e uma minoria, somente $8 \%$ dos entrevistados, não a empregam em suas atividades cotidianas.

Tendo em vista a relação que há entre o engenheiro ambiental, a educação ambiental e a busca pelo ecodesenvolvimento ou por padrões de desenvolvimento mais sustentáveis, verificou-se que a maioria dos entrevistados acredita na possibilidade de crescer economicamente e, simultaneamente, salvaguardar a conservação do meio ambiente. Entretanto, quanto ao desenvolvimento sustentável, observou-se que parte dos entrevistados o associa, equivocadamente, ao impacto zero e avaliam, sob tal perspectiva, que é impossível caminhar nesse sentido. Alguns entrevistados se referiram ao termo de forma acertada, porém fazem ressalvas em relação a sua implementação, justificando sua incompatibilidade com os moldes capitalistas.

\section{Referências}

BARBETTA, P. A. Estatística aplicada às ciências sociais. Florianópolis: Ed. UFSC, 2008.

BAUER, M. W; GASKELL, G. Pesquisa qualitativa com texto, imagem e som: um manual prático. 2. ed. Petrópolis: Vozes, 2003. 
BRÜGGER, P. Educação ou adestramento ambiental. Florianópolis: Letras Contemporâneas, 1994.

BRUGGER, P. Os novos meios de comunicação: uma antítese da educação ambiental? In: BAETA, A. M. B. et al. (Orgs.). Educação ambiental: repensando o espaço da cidadania. São Paulo: Cortez, 2002. 143-178.

BURSZTYN, M. Interdisciplinaridade: é hora de institucionalizar! Ambiente \& Sociedade, Campinas, v.2, n.5, p.229-231, Jul./Dez. 1999. Disponível em: <http://www.scielo.br/pdf/asoc/n5/n5a19.pdf>. Acesso em: 18 de mai. 2013.

CARVALHO, I. C. de M. Educação ambiental: a formação do sujeito ecológico. 2 ed. São Paulo: Cortez, 2006.

CHIZZOTTI, A. Pesquisa em ciências humanas e sociais. São Paulo: Cortez, 1991.

CRESPO, S. Educar para a sustentabilidade: a educação ambiental no programa da agenda 21. In: NOAL, F. O; REIGOTA, M; BARCELOS, V. H. de L. (Orgs.) Tendências da educação ambiental brasileira. Santa Cruz do Sul: EDUNISC, 1998.p.211-226.

D'AMBROSIO, U. Educação para compatibilizar desenvolvimento e sustentabilidade. Desenvolvimento e Meio Ambiente, Curitiba, v.15, n.15, p.11-20, Jan./Jun. 2007.

DIAS, G. F. Ecopercepção: um resumo didático dos desafios socioambientais. São Paulo: Gaia, 2004.

GIL, A. C. Metodologia do ensino superior. 2 ed. São Paulo: Atlas, 1994.

GOULARTI FILHO, A. Formação econômica de Santa Catarina. Florianópolis: Cidade Futura, 2002.

GUTIERREZ-MARTIN, F; HÜTTENHAIM, S. H. Environmental education: new paradigms and engineering syllabus. Journal of Cleaner Production, s/l, v.11, n.3, p. 247-251, May. 2003.

HORI, C. Y; RENOFIO, A. A inserção do engenheiro ambiental como garantia de uma evolução sustentável. In: ENCONTRO NACIONAL DE ENGENHARIA DE PRODUÇÃO, 18, Rio de Janeiro, 2008. Anais... Rio de Janeiro: ABEPRO, 2008. p.312-328. Disponível em: <http://www.abepro.org.br/biblioteca/enegep2008_TN_STO_079_547_11366.pdf >. Acesso em mai. 2013.

JACOBI, P. Educação ambiental, cidadania e sustentabilidade. Cadernos de Pesquisa, São Paulo, n.118, p.189-205, Mar. 2003.

LEAL FILHO, W. Meio ambiente: um tema de valor estratégico para a universidade brasileira. Ambiente \& Sociedade, São Paulo, Ano 2, n.5, p.191-201, Jul./Dez. 1999. Disponível em: <http://www.scielo.br/pdf/asoc/n5/n5a13.pdf>. Acesso em: 14 ago. 2013.

LEFF, E. Saber ambiental: sustentabilidade, racionalidade, complexidade, poder. Petrópolis: Vozes, 2001.

LIMA, G. F. da C. Crise ambiental, educação e cidadania: os desafios da sustentabilidade emancipatória. In: BAETA, A. M. B. et al. (Orgs.) Educação ambiental: repensando o espaço da cidadania. São Paulo: Cortez, 2002. p.109-142. 
LOUREIRO, C. F. B. Educação ambiental e movimentos sociais na construção da cidadania ecológica e planetária. In: BAETA, A. M. B. et al. (Orgs.) Educação ambiental: repensando o espaço da cidadania. São Paulo: Cortez, 2002. p.70-98.

MILIOLI, G. et al. O Sul do Estado de Santa Catarina. [Portal Uol/sites pessoais]. 2002. Disponível em: <http://vivimarc.sites.uol.com.br/aregiao.htm〉. Acesso em: 15 de jul. 2013.

MONTEIRO, V. V; PASQUALETTO, A. O engenheiro ambiental e seu campo de atuação em Goiás. 2007. Disponível em:

<http://www.ucg.br/ucg/prope/cpgss/ArquivosUpload/36/file/O\%20ENGENHEIRO\%20AMBI ENTAL\%20E\%20SEU\%20CAMPO\%20DE\%20TRABLHO.pdf $>$. Acesso em mai. 2013.

MONTIBELLER-FILHO, G. O mito do desenvolvimento sustentável: meio ambiente e custos sociais no moderno sistema produtor de mercadorias. 10 ed. rev. Florianópolis: Ed. da UFSC, 2008.

MORAES, E. C. de. A construção do conhecimento integrado diante do desafio ambiental: uma estratégia educacional. In: NOAL, F. O; REIGOTA, M; BARCELOS, V. H. de L. (Orgs.). Tendências da Educação Ambiental Brasileira. Santa Cruz do Sul: EDUNISC, 1998. p. 28-34.

MORIN, E. Por uma reforma do pensamento. In: PENA-VEJA, A; NASCIMENTO, E. P. (Orgs.). O pensar complexo: Edgar Morin e a crise da modernidade. Rio de Janeiro: Garamond, 1999.

PELICIONI, M. C. F; CASTRO, M. L. de; PHILIPPI Jr., A. A universidade formando especialistas em educação ambiental. In: PHILIPPI Jr., A; PELICIONI, M. C. F. Educação ambiental e sustentabilidade. Barueri: Manole, 2005. p. 218-265.

REIS, F. A. G. V. et al. Contextualização dos cursos superiores de meio ambiente no Brasil: engenharia ambiental, engenharia sanitária, ecologia, tecnólogos e sequenciais. Eng. Ambient., Espírito Santo do Pinhal, v.2, n.1, p.5-34, Jan./Dez. 2005. Disponível em: <http://189.20.243.4/ojs/engenhariaambiental/viewarticle.php?id=27>. Acesso em: 23 de mar. 2013.

RODRIGUES, M. G. Educação ambiental e sustentabilidade em países emergentes. In: SEABRA, G. Educação ambiental no mundo globalizado. João Pessoa: Editora Universitária/UFPB, 2011. p. 93-102.

SERVIÇO DE APOIO ÀS MICRO E PEQUENAS EMPRESAS - SEBRAE. Santa Catarina em números. Florianópolis: SEBRAE/SC, 2010. Disponível em: < http://www.sebraesc.com.br/scemnumero/>. Acesso em: 18 de mai. 2011.

TOZONI-REIS, M. F. de C. Educação ambiental: natureza, razão e história. Campinas: Autores Associados, 2004.

ZAMONER, M. Formação do engenheiro ambiental e educação ambiental: o caso da visita a empresa de saneamento urbano - S.A.U. Educação ambiental em ação, [online], n.25, s/p, 2008. Disponível em: <http://www.revistaea.org/artigo.php?idartigo=597\&class=02>. Acesso em: 10 de jun. 2013. 